\title{
Hemşireler ve Teknoloji-Durdurulamaz ve Kaçınılamaz İki Güç
}

\section{Nurses and Technology-Two Unstoppable and Inevitable Powers}

\author{
Merdiye Şendir ${ }^{1}$ (iD Ayşe Kabuk ${ }^{1}$ (iD
}

${ }^{1}$ Sağlık Bilimleri Üniversitesi, Hamidiye Hemşirelik Fakültesi, Hemşirelik Esasları Anabilim Dalı, İstanbul, TÜRKIYYE

Geliş tarihi/ Date of receipt: 05/04/2020 Kabul tarihi/ Date of acceptance: 23/04/2020

(C) Ordu University Faculty of Health Sciences, Department of Nursing, Turkey, Published online 30/04/2020

\section{ÖZ}

Hemşireler sağlık hizmetlerinin sunumunda ve toplum sağlı̆̆ını etkilemede hayati bir role sahiptir. Dünya Sağl1k Örgütü (DSÖ), 2020'yi "Uluslararası Hemşire ve Ebe Yılı" olarak belirlemiştir. Bugünlerde günlük hayatımızı büyük şekilde etkileyen pandemi gibi sorunlar ile bunun ne kadar önemli bir karar olduğunu açıkça görmekteyiz. Meslek örgütleri, akademisyenler ve klinik alanda çalışan hemşireler olarak, hemşireliğin önemi, sağlık sistemine sundukları katkı, bu katkıların görünür olması ve hemşirelik ile ilgili raporların iyileştirilmesinde bu yllı doğru değerlendirerek, firsata çevirebiliriz. Bunun için hemşirelerin girişimci olmaları, teknolojik ilerlemeleri benimsemeleri ve yönlerini dünyaya çevirmeleri gerekmektedir.

Anahtar Kelimeler: Hemşirelik, teknoloji, girişimcilik, dünya, pandemi

\begin{abstract}
Nurses play a vital role in influencing health care delivery and community health. The World Health Organization (WHO) has declared 2020 as the "International Nurse and Midwife Year". Nowadays, we see that this is an important decision with problems like pandemics that affect our life. As professional organizations, academics and nurses working in the clinical field, we can turn this year into an opportunity by correctly evaluating the importance of nursing, their contribution to the health system, the visibility of these contributions and the improvement of nursing-related reports. In order to achieve this, nurses need to be entrepreneurs, adopt technological advances and turn their directions into the World.
\end{abstract}

Keywords: Nursing, tecnology, entrepreneurship, world, pandemic

ORCID IDs of the authors: MŞ: 0000-0002-8243-1669, AK: 0000-0002-4741-5225

Sorumlu yazar/Corresponding author: Arş. Gör. Ayşe KABUK

Sağlık Bilimleri Üniversitesi, Hamidiye Hemşirelik Fakültesi, Hemşirelik Esasları Anabilim Dalı, Selimiye Mah. Tibbiye Cad. No:38 Üsküdar/İstanbul, TÜRKIYE

e-posta/e-mail: ayse.kabuk@ sbu.edu.tr

Atıf/Citation: Şendir M, Kabuk A. (2020). Hemşireler ve teknoloji-durdurulamaz ve kaçınılamaz iki güç. Ordu Üniversitesi Hemşirelik Çalışmaları Dergisi, 3(1), 52-56. DOI: 10.38108/ouhcd.713930 


\section{Giriş}

Hemşireler geçmişten günümüze eğitim, yönetim, araştırma ya da uygulama alanlarında birçok değişim yaşamıştır. Karşılaştığı değişimler ve güçlükler ile her alanda etkili baş etmesi gerekmiş, bu deneyimler sayesinde adaptasyon yeteneğinin önemini öğrenmiştir. Deneyimlerden, başarılardan ve hatalardan öğrendikleri ile geleceğin ihtiyaçlarına uyum sağlayabilmiş ve gelişebilmişlerdir. Bunun ilk örneği, Florence Nightingale'in Kırım Savaşı'nda verdiği hizmetlerle büyük bir değişimi başlatmasıdır. Karşılaştığı zorluklar ile verdiği mücadele, hemşireliğin toplumdaki ve kendi içindeki algısını dönüştürmüştür.

Bugünlerde yaşamımızı küresel olarak etkileyen sivil çatışmaları, göç sorunları, şiddet ve terör saldırıları, doğal afetleri ve pandemileri kapsayan olumsuz haberler duymaktayız (Shaffer, 2019). Tüm dünyayı etkisi altına alan Covid-19 pandemisinin vakaları artmaya devam ederken, Royal College of Nursing başkanı Nursing Times dergisinde yayınlamış olduğu yazısında, meslek örgütlerine kulak verilmesini, artan yoğun bakım ihtiyacını görmeyi ve bu nedenle kapasitenin acil olarak genişletilmesi gerektiğini vurgulamıştır. Bunun için gerekirse yeni emekli olan ve mezuniyetine 6 ay kalmış hemşire öğrencilerin hiçbir zorlama olmaksızın ve gerekli önlemler alınarak görevlendirilebileceğinden bahsetmiştir (Rafferty, 2020). Bunun yanında, teknoloji ve sağlık hizmet sunumunda da hızlı gelişmeler ve değişimler kaydedilmektedir. Tüm bu ilerlemeler hemşireliği ve sağlık sistemlerini sürekli gelişmeye ve değişmeye zorlamaktadır. Değişim gereken durumlara uyum sağlayabilmek için hemşirelere üç öneride bulunulmaktadır. Öncelikle daha girişimci olmaları, ikinci olarak teknolojik ilerlemeleri benimsemeleri ve son olarak da yönlerini dünyaya çevirmeleri önerilmektedir (Shaffer, 2019).

\section{Hemşirelerin Daha Girişimci Olmaları}

Dünya Sağlık Örgütü (DSÖ), 2020'yi "Uluslararası Hemşire ve Ebe Yılı" olarak belirlemiştir. Bununla, hemşirelerin eğitim, araştırma, yönetim ve uygulama alanlarında evrensel kaliteye ulaşmalarına katkı sağlamayı amaçlamıştır (WHO, 2019a). 2020 yilının seçilmesinin sebebi ise, modern hemşireliğin kurucusu Florence Nightingale'in doğumunun 200. yıldönümü ile aynı zamana denk gelmesidir. Nightingale'in belirttiği gibi, “... gözlem, yaratıcılık ve azim (bu özellikler gerçekten de iyi bir hemşirenin becerileridir), daha fazla hayat kurtarabilir" (Nightingale, 1969).

Dünya Sağlık Örgütü'nün "Hemşire ve Ebe Y1lı" ilan etmesi sağlik personeli istatistiklerine bakıldığında da anlamlı bulunmaktadır. Amerika Birleşik Devletleri'nde 2017 y1lında hekim sayısı 849 bin iken, hemşire sayısı 4 milyon 729 bin olarak rapor edilmiştir (WHO, 2019b). Ülkemizde Sağlık Bakanlığı'nın 2018 verilerine göre tüm sektörlerde 1 milyon sağl1k personeli bulunmaktadır ve 190 bini hemşire, 56 bini ebe, 153 bini hekim olarak görev yapmaktadır (T.C. Sağlık Bakanlığı, 2018). Ayrıca DSÖ'nün 2017 istatistiklerine göre her 10000 kişiye düşen hemşire sayısı Amerika'da 145, Fransa'da 111, Almanya'da 132, Türkiye'de ise 27 olarak rapor edilmiştir (WHO, 2019b). Diğer ülkelerin durumu ile karşılaştırdığımızda ülkemizde hemşire iş gücüne yatırımın artırılması gerektiğini görmekteyiz.

Uluslararası Hemşire Y1l, tarihimizi yansıtmak, toplumdaki hemşirelik imajını ve rolünü yeniden anlamlandırmak ve dünya genelinde toplum sağlığını geliştirmek için sosyal organizasyonlara katılma firsatlarını açmaktadır. Buna bir örnek olarak Amerikan Hemşireler Birliği (ANA), Birleşmiş Milletler Halk Sağlığı Servisi Hemşirelik Birimi, Kuzey Karolina Üniversitesi ve Washington Üniversitesi Hemşirelik Okulu işbirliği yaparak "Nurses Lead America to Health" isimli bir proje yürütmektedirler (Douglass, 2019). Ülkemizde de geniş kapsamlı ve halka doğrudan ulaşmayı amaçlayan projelerin hemşireler tarafindan yürütülmesi, hemşireliği ve değerini tanıtmayı sağlayacak en etkili girişimdir. 


\section{Hemşirelerin Teknolojik İlerlemeleri Benimsemeleri}

Çin'in Wuhan şehrinde 2019'un sonlarında bildirilen yeni bir koronavirüs olan COVID-19, hızla salgın haline geldi ve dünya çapında yayıldı. Bu süreçte yayılımı durdurmak için kısa ya da uzun süreli karantina, gönüllü ya da zorunlu sokağa çıkmama, sosyal mesafeyi koruma, seyahat kısıtlamaları gibi birçok önlemin alınmasını gerektirmiştir. $\mathrm{Bu}$ gerekliliklerin insanlar üzerinde anksiyete, travma sonrası stres bozukluğu, öfke gibi

olumsuz duyguları doğurabileceği belirtilmektedir. $\mathrm{Bu}$ süreçte sağlığın değerlendirilmesinde, sosyal desteğin sağlanmasında, eğitimde, haberleşmede ve sağlık hizmetlerinin sunumunda güvenle kullanabildiğimiz tüm yollar teknolojiden geçmektedir. Hemşireler, birey ve topluma kaliteli, nitelikli ve düşük maliyetli bakım sağlamak amacıyla bu süreci ve politikaları yönlendirerek, teknolojiyi bir değişim aracı olarak kullanmaktadır. Hemşireliğin doğasında bulunan inovatif kültür sayesinde bu süreci yönetme güçleri vardır (Moussa ve ark., 2018; Uzher ve ark. 2020).

Günümüzde sağlık hizmetlerine artan talebin karşılanması ve hemşirelik bakımının desteklemesinde, teknolojiden daha fazla faydalanılmasını gerektirmektedir. Sağlık hizmetleri artık elektronik sağlık kayıtları, reçete yazma araçları, tele-sağlı, çevrimiçi randevu planlama, mobil uygulamalar, tıbbi cihazlar, taşınabilir monitörler, akıllı hasta yatakları, giyilebilir biyosensörler gibi çok çeşitli teknolojilerden yararlanmaktadır. $\mathrm{Bu}$ teknolojilerin hayata geçirilmesinde, kullanılmasında ve geliştirilmesinde hemşirelerin çok büyük katkıları bulunmaktadır. Hemşire liderler bu nedenle dijital okuryazarlığ 1 iş gücüne entegre etmelidirler (Brysiewicz ve ark. 2015; Cassano, 2014). Sağlıkl1/hasta bireye bakım veren ve en yakınında olan hemşireler bireyin sağlığı ile ilgili tüm bilgiye kaliteli bakım verebilmek, güvenliğini sağlayabilmek ve hızlıca etkileşime girebilmek adına en kısa sürede sahip olmalıdırlar. Etkin kullanılan teknoloji, tıbbi ekipmanların israfını engeller, kaynakların düzgün kullanılmasını, kanıta dayalı uygulamay1, klinik karar verme desteği sağlayarak bakım standartlarını ve kalitesini iyileştirmeyi sağlamaktadır (Brysiewicz ve ark. 2015; Kleber ve Cohen, 2020).

Teknolojik gelişmeler kuşkusuz, gelecekteki eğitim, mesleki ve bireysel yaşamımızı etkilemeye devam edecektir. Teknolojiyi benimsemeli, hemşirelik ve sağlık hizmetlerine uygulanmasında lider olmalı ve günlük yaşamlarımızdaki faydalarını görmeliyiz.

\section{Hemşirelerin Yönlerini Dünyaya Çevirmeleri}

DSÖ ile Uluslararası Hemşireler Konseyi (ICN)'nin birlikte yürüttüğü "Hemşirelik ŞimdiNursing Now" projesi 2018'de başlatılmış ve 2020'nin sonuna kadar devam edeceği belirtilmiştir. $\mathrm{Bu}$ kampanya, beș temel alana odaklanan bir işbirliğini kapsamaktadır (Nursing Now, 2020; Barton, 2020). Bu alanlar;

- Sağlık politikası yapımında hemşirelerin ve ebelerin daha fazla söz sahibi olmalarının sağlanmasi.

- Hemşirelik iş gücüne daha fazla yatırım yapılmasının teşvik edilmesi.

- Liderlik pozisyonlarında hemşirelerin daha fazla bulunmasinın desteklenmesi.

- Hemşirelerin en büyük etkiyi nerede sağlayabileceğini belirlemeye yardımcı olan araştırmaların teşvik edilmesi.

- İyi hemşirelik uygulaması örneklerinin paylaşılması.

Hemşireler olarak bizler, sağlık politikalarını geliştirmek için küresel ve ulusal hareketleri yakından takip etmeli ve gerektiğinde yanıt vermeliyiz. Hemşirelik felsefesine uygun olmayan politika ve uygulamalara karşı çıkmak için bireysel veya örgütsel olarak sorumluluklarımız bulunmaktadır. Ayrıca, öğrenci hemşirelerin, politika ve uygulamalardaki sorumluluklarını, hemşirelerin rol ve sorumluluğu olarak tanıması için liderlik ve politika çalışmalarını eğitim müfredatına önemli oranda dahil etmeliyiz. Journal of Nursing Education dergisi editörü Barton, derginin Ocak 2020 sayısında, hemşirelik okullarında hemşireliğin sosyal misyonunun 
kurumsal olarak tanımı olup olmadığını, eğer var ise nasıl yürütüldüğünü, sosyal misyonun terfi ve görev ölçütlerinde tanınıp tanınmadığını sorgulamıştır (Barton, 2020). Okullarda öncelikle birey ve topluma odaklanan daha sonra öğrenciler için öğrenme firsatları sağlayan sosyal ortaklıklar bulunmalıdır. Sağlığın sosyal belirleyicileri olan hemşire öğrencilerin öğrenme etkinlikleri müfredatta yer almalı ve tutarlı olmalıdır.

Pittman (2019) tarafindan ortaya atılan olası bir çözüm de, Lillian Wald tarafından oluşturulan toplum temelli ve birey merkezli hemşirelik modeline geri dönmektir. Model tarafından belirlenen ilkeler dikkate alındığında, toplumda hemşireliğin dört temel işlevi ortaya çıkmaktadır:

- Birey, aileler ve topluma güven verme.

- Hastaların sağlığını etkileyen durumları tespit etmede kapsamlı bir şekilde sağlık tanılamas1 yapma.

- Sağlığı geliştirmek için sağlık kurumları dışında sosyal ve ekonomik kuruluşlarla ortaklıklar geliştirme.

- Toplumdaki farklılıkları ve sağlığı destekleyerek, toplu şekilde sağlığın üst basamaklara çıkmasını sağlama ile ilgili çözümler üretme (Buhler-Wilkerson, 1993).

Dünyadaki gelişmeleri yakalamak ve katkılar verebilmek için ülkemizde de hemşireliğin sorunlarını görüşmek, yönetimini tartışmak, iyi uygulama örneklerini paylaşmak, araştırma bilgisini geliştirmek, teknolojiyi ve inovasyonu desteklemek için yıl boyunca faaliyetler planlanmaktadır (THD, 2019).

\section{Sonuç ve Öneriler}

Covid-19 pandemisi sürecinde mesleğimizi güçlendiren adımlarla Ülkemizde ve Dünyada yaşananları kaydetmekteyiz. Meslek örgütleri, akademisyenler ve klinik alanda çalışan hemşireler olarak her zaman sorunlara çözüm olmak için birlikte olduğumuz unutulmamalıdır. 2020 Hemşire Y1l, Nightingale'in doğumunun 200. y1ldönümüdür. Topluma en yakın sağlık profesyonelleri olan hemşireler, sağlık ekibinin kalbinde yer alır. Toplum temelli bakımın yeni modellerinin geliştirilmesinde özel bir role sahiptirler ve girişimci kültürleri, teknolojik becerileri, geniş vizyonları ile dünyanın geleceğini desteklemektedirler.

Teknoloji sürekli değişmekte, hemşirenin hayatını kolaylaştıracak yeni ve daha iyi yöntemlere dönüşmektedir. Hemşireler teknolojiye kuramsal bilgilerini kattıklarında ve kullandıklarında güçlerini daha fazla artıracaklardır.

Araştırmanın Etik Yönü/ Ethics Committee Approval: Literatür taraması yapıldı, derlemede kullanılan kaynaklar bölümünde gösterildi.

Hakem/Peer-review: Diş hakem değerlendirmesi.

Yazar Katkısı/Author Contributions: Fikir/ kavram: MS, AK; Tasarım: MS; Danışmanlık: MS, AK; Analiz ve/veya Yorum: MS; Kaynak tarama: MS, AK; Makalenin Yazımı: MS, AK; Eleştirel inceleme: MS, AK.

Çıkar çatışması/Conflict of interest: Çalışmada herhangi bir çıkar çatışması söz konusu değildir.

Finansal Destek/Financial Disclosure: Herhangi bir finansal destek alınmamıştır.

\section{Çalışma Literatüre Ne Kattı?}

- Teknolojinin hemşirelik için önemini ortaya koymaktadir.

- Dünya Sağlık Örgütü tarafından ilan edilen Hemşire Yılı'nın güncel önemini açıklamaktadır.

- Ülkemizde Hemşire Yılı'nın farkındalığına katkı sağlamaktadır.

- Hemşireliğin sağlık bakım sistemindeki gücünü ifade etmesi için yol göstermektedir.

\section{Kaynaklar}

Barton AJ. (2020). International Year of the Nurse and Midwife. Journal of Nursing Education. 59(1):3-4.

doi:10.3928/01484834-20191223-01 
Brysiewicz P, Hughes TL, Mccreary LL. (2015). Promoting innovation in global nursing practice. Rwanda Journal Series F: Medicine And Health Sciences. 2 (2).

Buhler-Wilkerson K. (1993). Bringing care to the people: Lillian Wald's legacy to public health nursing. Am J Public Health, 82(12): 1778-1786.

Cassano C. (2014). The Right BalanceTechnology and Patient Care. Healthcare Information and Management Systems Society. Erişim Tarihi 05.04.2020 https://www.himss.org/resources/rightbalance-technology-and-patient-care

Douglass C. (2019). Nursing Now USA initiative launches. Erişi Tarihi 10.04.2020 https://nursing.uw.edu/article/nursing-nowusainitiative-launches/

Kleber J, Cohen B. (2020). Reducing Waste and Increasing Sustainability in Health Care Settings. American Journal of Nursing. 120(4), 45-48.

Moussa M, Mcmurray A, Muenjohn N. (2018). A conceptual framework of the factors influencing innovation in the public sector organizations. The Journal of Developing Areas. 52(3).

Nightingale F. (1969). Notes on nursing: What it is andwhat it is not. New York, NY: Dover Publications.

Nursing Now. (2020). Who we are. Erişim Tarihi 02.03.2020 https://www.nursingnow.org/who-we-are/

Pittman P. (2019). Rising to the challenge: Reembracingthe Wald model of nursing. American Journal of Nursing, 119 (7),4652.doi:10.109
Rafferty AM. (2020). Covid-19 is the biggest challenge for nursing since Nightingale. Nursing Times. Erişim Tarihi 02.04.2020 https://www.nursingtimes.net/opinion/covi1 9-is-the-biggest-challenge-for-nursingsince-nightingale-27-03-2020/

Shaffer FA. (2019) "Overview and Summary: Past, Present, and Future: Nurses Address the Times of OurLives" OJIN: The Online Journal of Issues in Nursing, 24 (2). doi:10.3912/OJIN.Vol24No02ManOS

T.C. Sağlık Bakanlığı Sağlık İstatistikleri Y1llı̆g 1 2018. Sağlık Bilgi Sistemleri Genel Müdürlüğü, Ankara, 2019. Erişim Tarihi 02.03 .2020

https://dosyasb.saglik.gov.tr/Eklenti/36134,s iy2018trpdf.pdf?0

Türk Hemşireler Derneği (THD). (2019). Dünya Hemşireler Yılı THD Genel Merkez Faaliyetleri. Erişim Tarihi 13.04.2020 https://www.thder.org.tr/nursing-nowturkey

Uzher K, Bhullar N, Jackson D. (2020). Life in the pandemic: Social isolation and mental health. Journal of Clinical Nursing. doi: 10.1111/jocn.15290.

World Health Organization. (2019a). Executive board designates 2020 as the "Year of the Nurse and Midwife.". Erişim Tarihi 02.03.2020

https://www.who.int/hrh/news/2019/2020ye ar-of-nurses/en/

World Health Organization. (2019b). Welcome to Global Health Work force Statistics. Erişim Tarihi 02.03.2020

http://apps.who.int/gho/data/node.main.HW FGRP?lang=en 